\title{
CAN INTERNATIONAL TRIP EXPERIENCES AT DMU (\#DMUGLOBAL, UK) PROVIDE TRANSVERSAL \& WORK COMPETENCES?
}

\author{
A. Peña-Fernández ${ }^{1}$, M.C. Lobo-Bedmar ${ }^{2}$, M.A. Peña ${ }^{3}$ \\ ${ }^{1}$ De Montfort University, Faculty of Health and Life Sciences (UNITED KINGDOM) \\ ${ }^{2}$ IMIDRA, Departamento de Investigación Agroambiental (SPAIN) \\ ${ }^{3}$ Universidad de Alcalá, Unidad de Farmacia y Tecnología Farmacéutica, Departamento de \\ Ciencias Biomédicas (SPAIN)
}

\begin{abstract}
De Montfort University (DMU, Leicester, UK) is highly committed to promote different strategies to facilitate the acquisition of the key transversal competences and skills recently defined by the European Union for future students in the European Higher Education Area (European Commission, May 2017) [1], including skills to manage complex information and resolve complex global challenges, capabilities for creative and autonomous thinking, effective communication, engagement with local communities and promotion of social inclusion and mobility. To promote internationalisation, DMU developed a specific programme named \#DMUglobal in September 2013 that includes the European mobility programmes (Erasmus+) and DMU academic-led trips. The \#DMUglobal trips involve a shortterm visit to another country that is offered to any DMU student. To the best of our knowledge, \#DMUglobal provides one of the most comprehensive international experience programmes at any UK university. The DMU Faculty of Health \& Life Sciences offered a novel \#DMUglobal trip to visit New York (NYC, US) in the 2017/18 academic course to determine potential public health risks due to environmental contamination by carbon monoxide (CO). A total of 45 students from different programmes, specifically BSc Biomedical Science, BMedSci Medical Science and BSc Healthcare Science (Audiology), visited NYC in January 2018 for 5 days together with two academics that supervised the different activities. Briefly, students were divided into small groups to measure levels of CO from different locations in NYC using small CO detector devices. Once they returned to DMU, students analysed the collected data to determine any potential human risks and completed a poster by the end of January 2018. Posters were peer-reviewed by these students, which selected the best one to be presented at a DMU research conference in Summer 2018. We used qualitative and quantitative methods to analyse whether students that undertook this international experience gained some of the above competences and other such as the memo factors (curiosity, confidence, serenity, decisiveness and vigour). Thirty students completed a feedback-questionnaire, which showed high levels of enjoyment in participating in this novel global trip (43.3\% agreed, $50 \%$ strongly agreed) and pointed to teamwork as the best part of the $\mathrm{CO}$ monitoring activity. Furthermore, $83.3 \%$ indicated that they gained or improved specific skills such as communication, engagement with local communities and broadened their cultural horizons (33.3\% agreed, 50\% strongly agreed). Also, $73.3 \%$ highlighted that they gained some presentation skills and $70 \%$ described that producing the poster helped them to understand the topic. Moreover, $73.3 \%$ of students that completed the questionnaire indicated that they will use the knowledge learnt in their studies. In the open answer questions, students suggested some improvements for future trips including the provision of more sensitive $\mathrm{CO}$ monitors and the creation of extra activities relevant for biomedical science. These results could indicate that the \#DMUglobal trips could be an effective strategy to facilitate and promote many of the key competences described.
\end{abstract}

Keywords: \#DMUglobal, internationalisation, transversal competences, work skills, student satisfaction.

\section{INTRODUCTION}

Internationalisation, defined as "the process of integrating an international, intercultural, or global dimension into the purpose, functions or delivery of post-secondary education" [2], has emerged as a critical element for providing an overall experience to any higher education (HE) student. Thus, the recent European Union (EU) agenda for higher education [1] outlines a series of policy priorities for $\mathrm{HE}$ including the promotion of mobility and international cooperation, to provide students with 
important transversal competences (capacities for entrepreneurship and resilience, skills to manage complex information and resolve complex global challenges, capabilities for creative and autonomous thinking, effective communication, engagement with local communities and promotion of social inclusion and mobility) and transferable skills for enhancing their employability in a globalised market [1-3].

To promote internationalisation, De Montfort University (DMU, Leicester, UK), established in 2013 a specific programme named \#DMUglobal that involves the Erasmus programme and creates other opportunities to facilitate provision to any DMU student an accessible opportunity for an international experience such as the novel DMU academic-led trips (\#DMUglobal trips), which involve a short-term visit to another country. Thus, to the best of our knowledge, \#DMUglobal provides one of the most comprehensive international experience programmes at any UK university. More information about the programme and current opportunities for DMU students can be found on the \#DMUglobal website (Figure 1; [4]).

DMU launched a special \#DMUglobal trip scheme for final year students to visit New York (NYC, United States) in 2016/17 for which all the DMU Faculties can apply. Our School of Allied Health Sciences was funded to perform a trip with our students to assess the human risks to environmental contamination or carbon monoxide (CO) in NYC early this January 2018. The main aim of this trip was to enhance students' general knowledge of global health, as recent studies have reported the necessity of enhancing the current status of the teaching of this subject to future health care professionals [5]. Internationalisation can also facilitate teaching relevant aspects of global health (including the effect of environmental pollution on human health) and the acquisition of intercultural competences.

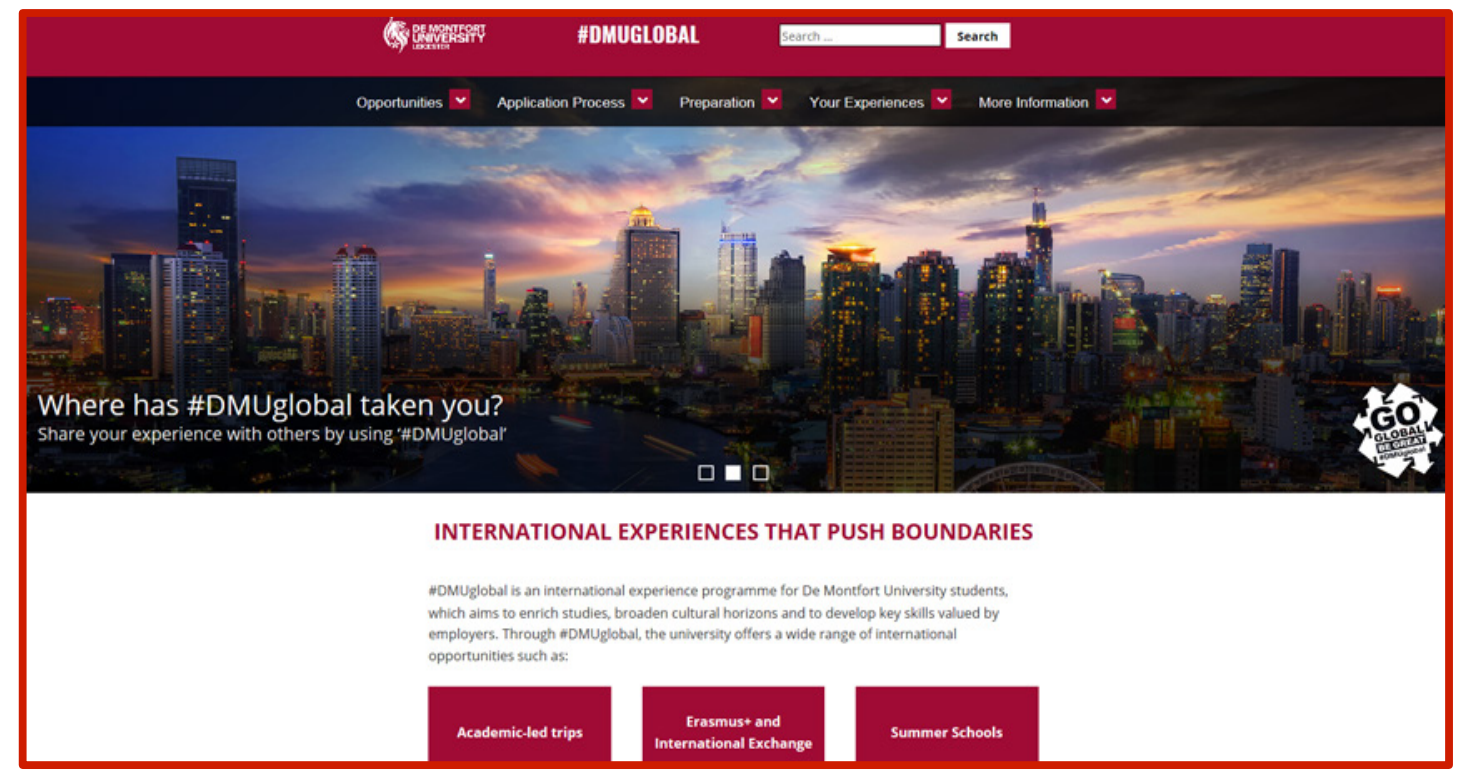

Figure 1. Overview of the \#DMUglobal website. Available at: https://www.dmuglobal.com/

\section{1 \#DMUglobal New York 2018 trip}

A description of the trip can be found in Peña-Fernández et al. (2018) [6], but briefly: 45 students from three programmes [BSc Biomedical Science, BMedSci Medical Science and BSc Healthcare Science (Audiology)] travelled to NYC on the $4^{\text {th }}$ January 2018 for 5 days to perform an environmental human health risk assessment study in combination with other different activities. These students, in groups, took different measurements of the levels of carbon monoxide (CO) across NYC using small CO detector devices. Groups created a scientific poster with the results obtained after determining human health risks according to the data gathered; groups also tailored potential interventions to tackle the levels of $\mathrm{CO}$ found and protect human health. Posters were presented, assessed and peer-reviewed in a special workshop session created on the 26th January 2018. To encourage participation, as this session was voluntary, students/groups were asked to select the best poster to create a follow up abstract to be submitted to be considered for presentation in the School of Allied Health Sciences Research Conference 2018 (SAHRC, to be held July 2018). An overview of some of the posters presented to this special workshop is shown in Figure 2. 


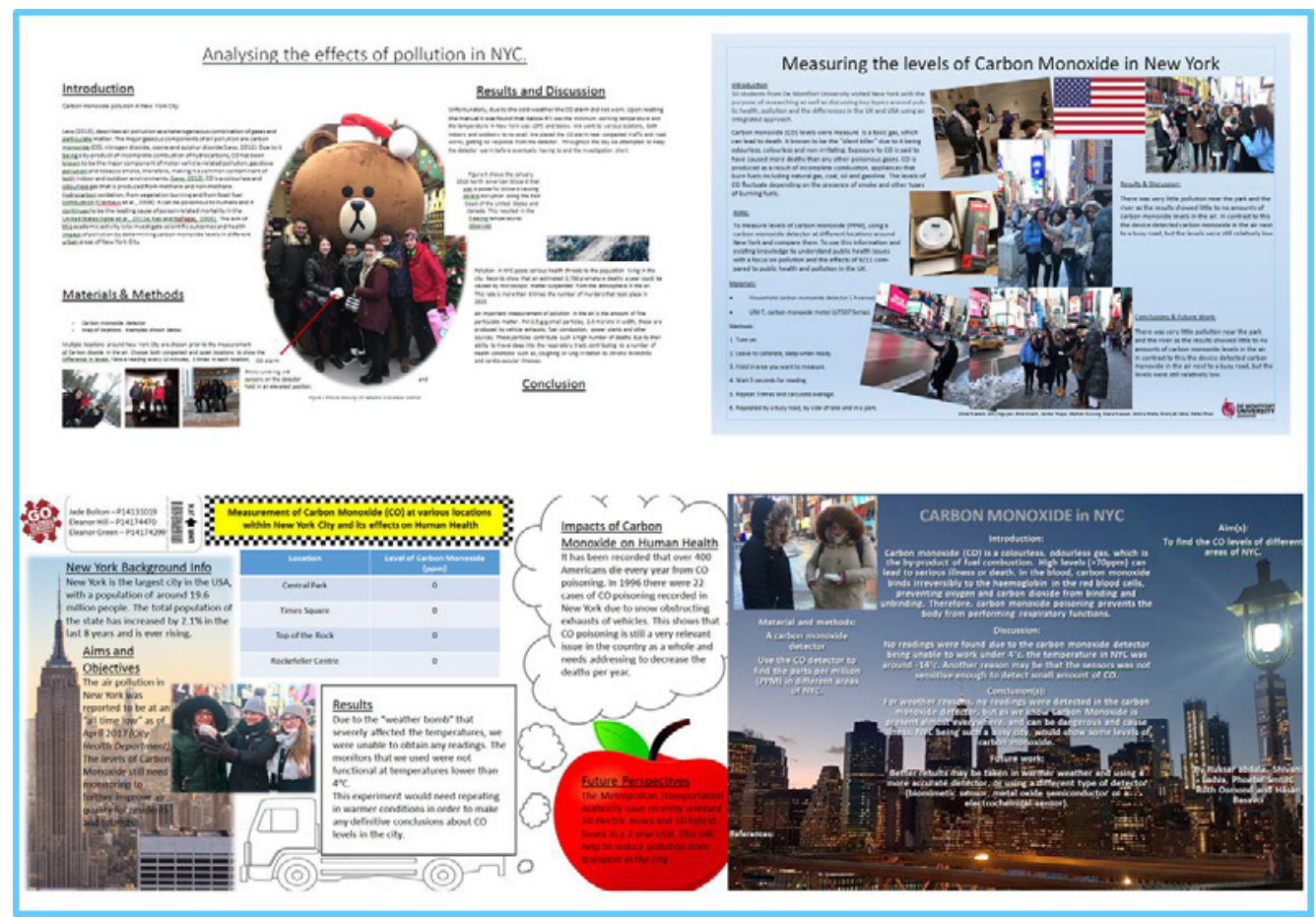

Figure 2. Overview of some of the posters presented by students.

\subsection{Aims}

The aims of this paper were to assess if this \#Global trip was effective in facilitating the acquisition of different transversal and intercultural competences as well as some of the mobility competencies defined by Erasmus (named memo $^{\odot}$ factors; [7]): curiosity, confidence, serenity, decisiveness and vigour).

\section{METHODOLOGY}

We used qualitative and quantitative methods to explore the aims highlighted above. Briefly, we analysed the students' performance during the workshop session in which they peer-reviewed the posters as well as their level of interaction and engagement in this extra-activity. A feedbackquestionnaire to evaluate the suitability of our trip experience to deliver the proposed competences was provide electronically to all students. The questionnaire had a series of Likert scale and openanswer questions so the students could comment on their overall experience and suggest improvements. Students were informed about the purpose of the project and anonymously completed the questionnaire. Ethical approval was granted by the Research Ethics Committee at De Montfort University (HLS FREC Ref: 3038; Jan 2018).

\section{RESULTS}

The \#DMUglobal academic-led trip was overwhelmingly well-received as evidenced by their favourable evaluation. Most students were actively involved in the production, defence and peerevaluation of the posters. Students were shown to have acquired most of the memo ${ }^{\odot}$ factors, specifically curiosity, confidence and vigour, if we are taken into account the high level of interaction and discussion generated in this activity in conjunction with the scientific appropriateness of the posters produced. Students verbally indicated that they felt more confident and decisive.

Thirty students our of forty five completed the specific feedback-questionnaire, which showed high levels of enjoyment in participating in this novel global trip $(43.3 \%$ agreed, $50 \%$ strongly agreed; Figure 3 ) and pointed to teamwork as the best part of the $\mathrm{CO}$ monitoring activity. 


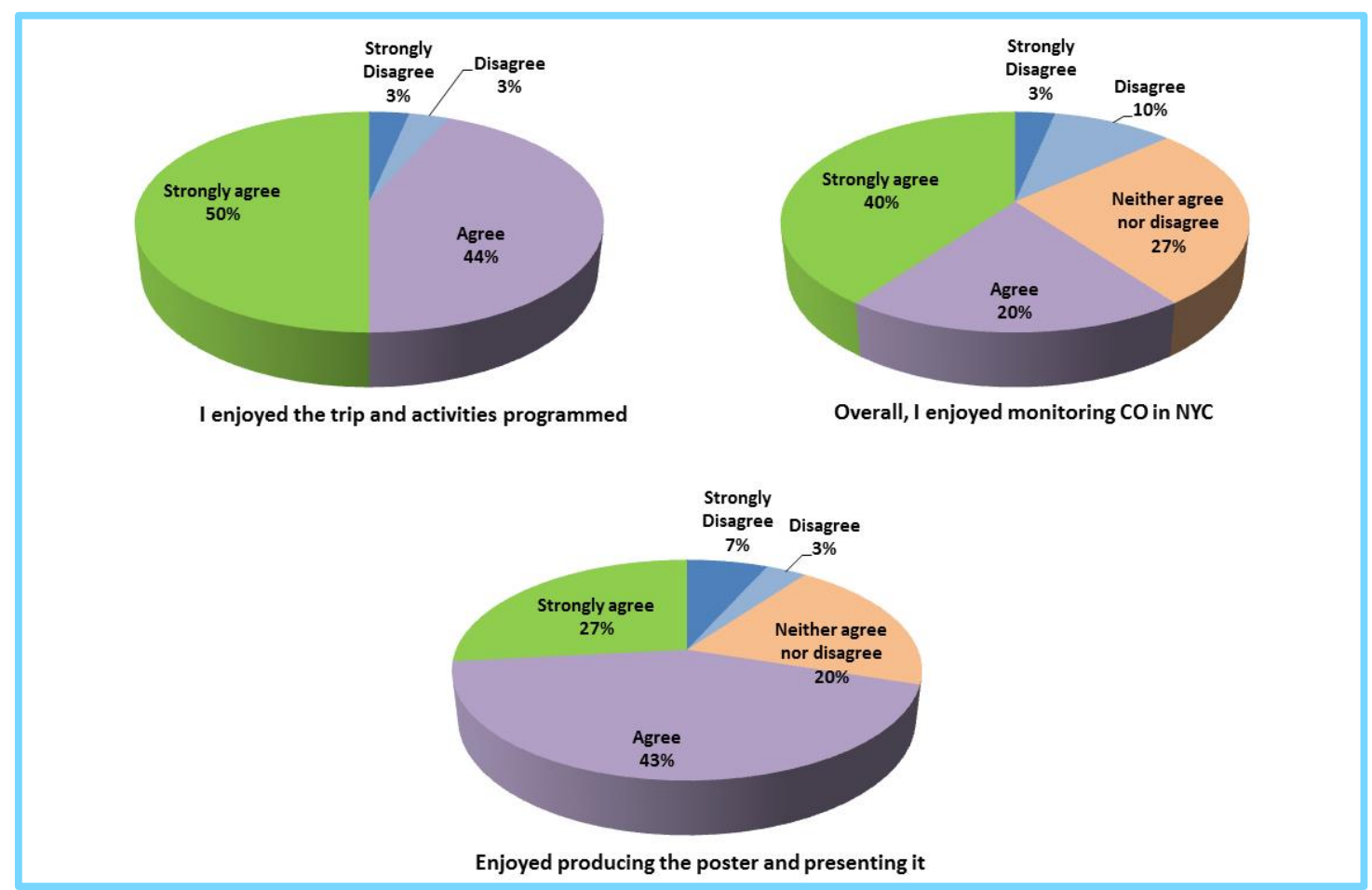

Figure 3: \#DMUGlobal New York 2018 trip survey results showing percentage of responses for questions related with students' enjoyment and satisfaction. Absence of a Likert category indicates no responses for that category.

The majority of participants indicated that they acquired international and mobility competences during this international trip experience, as highlighted in Figure 4 . Specifically, $83.3 \%$ indicated that they gained or improved specific skills such as communication, engagement with local communities and a similar percentage reported that the trip broadened their cultural horizons $(33.3 \%$ agreed, $50 \%$ strongly agreed).

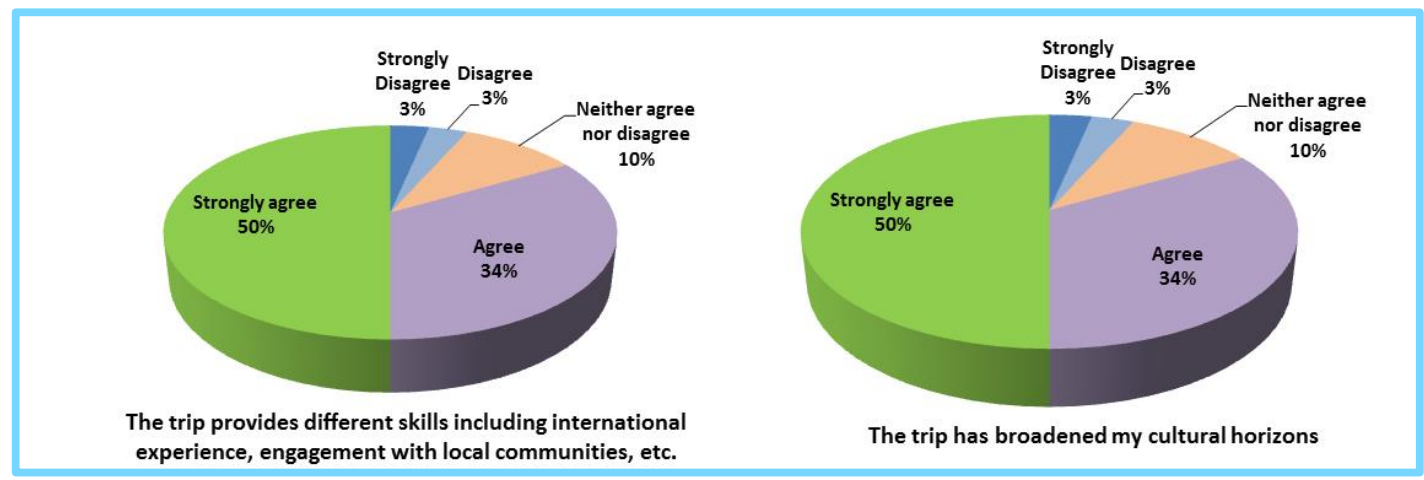

Figure 4: \#DMUGlobal New York 2018 trip survey results showing percentage of responses for questions related with students' acquisition of international and mobility competences.

Finally, a high level of students highlighted the benefits of participating in a global trip for their studies overall and the acquisition of relevant transversal competences. Thus, $73.3 \%$ highlighted that they gained some presentation skills and $70 \%$ described that producing the poster helped them to understand the topic. Moreover, $73.3 \%$ of students that completed the questionnaire indicated that they will use the knowledge learnt in their studies. 


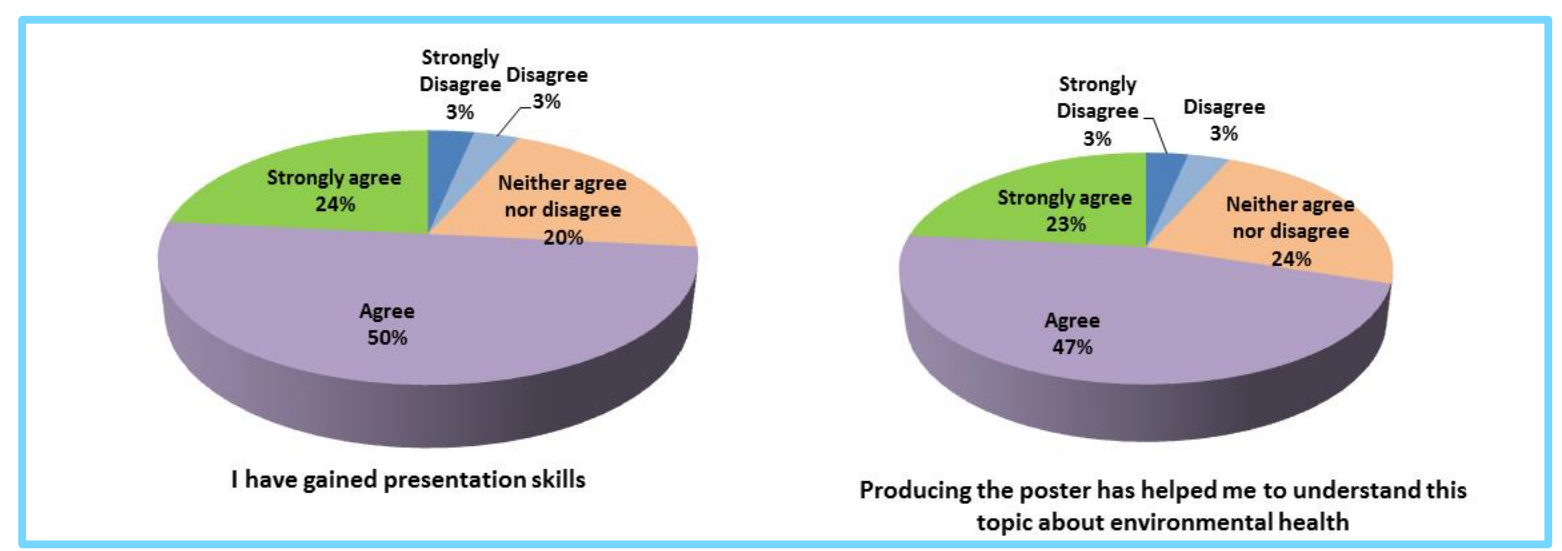

Figure 5: \#DMUGlobal New York 2018 trip survey results showing percentage of responses for questions related with students' acquisition of transversal competences and comprehension.

In the open answer questions, students suggested some improvements for future trips including the provision of more sensitive $\mathrm{CO}$ monitors and the creation of extra activities relevant for biomedical science. Finally, students gained an idea of the importance of the environment in human health.

\section{CONCLUSIONS}

The analysis of the overall results would indicate that the organised \#DMUglobal academic-led trip to New York was successful in providing students with different international, mobility and transversal competences (including critical thinking, research skills, communication and team work) as well as most of the $\mathrm{memo}^{\odot}$ factors described (curiosity, confidence, serenity, decisiveness and vigour). Despite this, more specific studies are needed to establish the degree of acquisition of these skills and competences, our results indicate that \#DMUglobal academic-led trips could be an excellent platform for promoting internationalisation, mobility and acquisition of many of the competences highlighted in the recent EU agenda for higher education.

\section{ACKNOWLEDGEMENTS}

The authors would like to express their sincere appreciation to DMU and the School of Allied Health Sciences for organisation and funding the \#DMUglobal trip to NYC 2018. Moreover, we would like to give special thanks to Dr Charlotte Rogers and all the \#DMUglobal team and DMU media that have made this trip possible. Finally, we want to give thanks to all our students for their participation and interest in this project that made this an unforgettable experience in NYC.

\section{REFERENCES}

[1] Communication from the Commission to the European Parliament, the Council, the European Economic and Social Committee and the Committee of the Regions on a renewed EU Agenda for Higher Education COM(2017) 24730 May 2017. Available at: http://eur-lex.europa.eu/legalcontent/EN/TXT/?qid=1496304694958\&uri=COM:2017:247:FIN [accessed 24/04/2018]

[2] J. Knight, "Updating the definition of internationalization," Int Higher Edu 2015; vol.33, issue 2-3, 2015.

[3] H.J. Standley. "International mobility placements enable students and staff in Higher Education to enhance transversal and employability-related skills" FEMS Microbiol Lett., vol 362, issue 19, 2015.

[4] \#DMUglobal website. Available at https://www.dmuglobal.com/ [accessed 10/05/2018]

[5] Ambrose M, Murray L, Handoyo NE, Tunggal D, Cooling N. Learning global health: a pilot study of an online collaborative intercultural peer group activity involving medical students in Australia and Indonesia. BMC Med Educ. 2017; 17(1):10. https://doi.org/10.1093/femsle/fnv157

[6] Peña-Fernández A., Evans MD., Fretwell L., Peña MA. Promoting internationalisation in human health degrees. INTED2018 Proceedings; 8797-8802. ISBN 978-84-697-9480-7. 
[7] European Commission, 2016. The Erasmus Impact Study. Regional Analysis. Available at: http://ec.europa.eu/dgs/education_culture/repository/education/library/study/2016/erasmusimpact_en.pdf [accessed 10/05/2018] 